\title{
Peranan Masyarakat Lokal Desa Kukuh dalam Pengelolaan Daya Tarik Wisata Alas Kedaton, Kabupaten Tabanan
}

Anak Agung Bagus Yoga Pratama a,1 Gde Indra Bhaskaraa,2

1agunkyogapratama@gmail.com² gbhaskara@unud.ac.id

a Program Studi Sarjana Destinasi Pariwisata, Fakultas Pariwisata, Universitas Udayana, Jl. Dr. R. Goris, Denpasar, Bali 80232 Indonesia

\section{Abstract}

Alas Kedaton tourist is a natural tourist attraction. The tourist attraction offered such as forests, monkeys and bats in this natural attraction. In the middle of the Alas Kedaton forest there is a Dalem Kahyangan Kedaton temple that is unique. The choice of this location as a place of research is to find out how the management and role of the local community of Kukuh Village in developing Alas Kedaton as a tourist attraction.

The research methodology used is this study is a descriptive qualitative research, with observation, interview, literature study and documentation techniques. Data sources are obtained from primary data and secondary data. The theory or concept used is the concept of role, local society, tourist attraction and management.

The result of this research is that management in Alas Kelaton tourist attraction involves local communities actively. The involvement and role of the local community of Desa Kukuh is empowered to become a member of the management body, counter staff, janitors, local guides, security officers, Alas Kedaton Trader Group (KPAK) and as well as forming tourism awareness organisations such as tourism awareness groups (Pokdarwis).

\section{Keywords: The Role of Local Communities,Management, Tourist Attractions}

\section{PENDAHULUAN}

Sektor Pariwisata merupakan salah satu sektor yang dapat mendorong perekonomian negara karena mampu memberikan pendapatan dalam bentuk devisa. Tidak heran jika disetiap Negara mulai banyak mengembangkan daerahnya menjadi destinasi wisata karena memang memberikan keuntungan. Termasuk juga di Indonesia, Indonesia merupakan negara yang memiliki banyak keindahan alam dan keanekaragaman suku serta budaya yang tersebar diseluruh pelosok Indonesia. Di Indonesia daerah atau kawasan yang dianggap memiliki potensi wisata mulai banyak dikembangkan menjadi destinasi wisata.

Sektor pariwisata merupakan salah satu aspek penting dalam suatu wilayah. Bila dikembangkan dengan baik maka akan menjadi suatu potensi yang dapat meningkatkan pendapatan perekonomian daerah tersebut. Pada pembangunan pariwisata dibutuhkan adanya kerjasama yang baik antara pihak pemangku kepentingan (Stakeholder) pariwisata yakni, antara pemerintah, masyarakat lokal, dan pihak swasta/investor sehingga nantinya dapat terjadi keseimbangan dalam pembangunan pengembangan pariwisata.

Bali merupakan salah satu destinasi wisata yang sangat berkembang pesat di Indonesia. Pulau Bali terkenal akan kebudayaannya yang unik dan memiliki keindahan alam yang sangat indah. Salah satu destinasi wisata yang ada di Bali yaitu Alas Kedaton.

DTW Alas Kedaton terletak di Desa Kukuh, Kecamatan Marga, Kabupaten Tabanan. DTW Alas Kedaton merupakan destinasi wisata yang berbasis wisata alam. Daya tarik yang diunggulkan yaitu berupa sesuatu yang disediakan langsung oleh alam seperti hutan dan kera - kera serta kelelawar (kalong) yang ada di DTW Alas Kedaton. Dalam pengelolaan DTW Alas Kedaton, pihak pengelola melibatkan masyarakat lokal dalam pengelolaan dan pengembangannya. Peran Pemangku Kepentingan (Stakeholder) pariwisata dalam pengembangan destinasi wisata memanglah sangat penting, salah satunya ialah peranan dari masyarakat lokalnya. Pengembangan suatu destinasi wisata tidak lepas dari keterlibatan masyarakat lokal sebagai pemilik dari destinasi.

Pada akhir tahun belakangan ini di DTW Alas Kedaton mengalami penurunan jumlah kunjungan wisatawan baik itu jumlah kunjungan wisatawan nusantara maupun jumlah kunjungan wisatawan mancanegara. Oleh sebab itu, penelitian ini bertujuan untuk mengidentifikasi bagaimana peranan dari masyarakat lokal Desa Kukuh dalam upaya pengelolaan dan pengembangan DTW Alas Kedaton 


\section{LANDASAN KONSEP}

Landasan konsep yang digunakan dalam penelitian ini, yakni sebagai berikut:

1. Konsep Peranan

Peranan (role) merupakan proses dinamis kedudukan (status). Apabila seseorang melaksanakan hak dan kewajibannya sesuai dengan kedudukannya, dia menjalankan suatu peranan. Perbedaan antara kedudukan dengan peranan adalah untuk kepentingan ilmu pengetahuan. Keduanya tidak dapat dipisahpisahkan karena yang satu tergantung pada yang lain dan sebaliknya (Soekanto, 1990).

Ditinjau dari tugas, peranan itu dibagi menjadi dua yaitu :

a. Peranan Aktif, yaitu : Pelaku tersebut harus melakukan tugasnya pada saat dan tempat secara tepat.

b. Peranan Pasif, yaitu : Tanpa adanya seseorang tersebut ikut kegiatan dalam masyarakat, kegiatan itu akan tetap berjalan lancar.

Peranan dalam penelitian ini yakni suatu fungsi atau aspek aktif dari seseorang atau kelompok sosial/masyarakat lokal didalam melakukan hak dan kewajibannya sesuai dengan kedudukannya sebagai pengelola di Daya Tarik Wisata Alas Kedaton.

2. Konsep Pengelolaan

Pengelolaan yaitu suatu kegiatan yang dilakukan oleh beberapa orang atau individu, dimana kegiatan tersebut menyangkut planning (perencanaan), organizing (pengorganisasian), actuating (pergerakan), dan controling (pengawasan) (Terry, 2009).

3. Konsep Daya Tarik Wisata

Daya tarik wisata adalah segala sesuatu yang memiliki keunikan, keindahan dan nilai yang berupa keanekaragaman kekayaan alam, budaya, dan hasil buatan manusia yang menjadi sasaran manusia atau tujuan kunjungan wisatawan (Undang - undang nomor 10 Tahun 2009)

4. Konsep masyarakat Lokal

Suatu kelompok masyarakat yang hidup dan bekerja sama dalam suatu ikatan sosial dan telah bertempat tinggal dalam suatu lokalitas wilayah geografis dengan batas yang jelas secara tetap dan turun - menurun dalam waktu yang sangat lama sehingga membentuk rasa solidaritas sosial yang kuat (Lawang, 1992).

\section{III.METODE PENELITIAN}

Penelitian ini dilakukan di DTW Alas Kedaton, Desa Kukuh, Kecamatan Marga, Kabupaten Tabanan, Bali. Pada akhir tahun belakangan ini di DTW Alas Kedaton mengalami penurunan jumlah kunjungan wisatawan. Adapun ruang lingkup penelitian dalam penelitian ini yakni: Peranan dari masyarakat lokal Desa Kukuh dalam kegiatan Perencanaan, Pengorganisasi, Pergerakan, dan Pengawasan yang dilakukan untuk pengembangan DTW Alas Kedaton. Jenis data dalam penelitian ini adalah data kualitatif yakni data yang berupa uraian informasi atau keterangan yang meliputi uraian tentang gambaran umum Desa Kukuh dan profil DTW Alas Kedaton, pengelolaan serta peranan masyarakat Desa Kukuh dalam mengembangkan DTW Alas Kedaton. Sumber data dalam penelitian ini yaitu ada data primer dan data sekunder, data primer yaitu merupakan hasil wawancara serta hasil pengamatan di lapangan dan data sekunder adalah data yang didapat dari hasil studi kepustakaan DTW Alas Kedaton.

Metode pengumpulan data yang digunakan dalam penelitian ini, yaitu: melakukan pengamatan (observasi), wawancara mendalam, studi kepustakaan dan dokumentasi yang digunakan untuk mendapatkan informasi yang lebih banyak mengenai potensi, pengelolaan yang telah dilakukan, partisipasi serta peranan dari masyarakat lokal Desa Kukuh dalam upaya pengembangan DTW Alas Kedaton. Metode yang digunakan untuk menentukan informan adalah menggunakan prosedur Purposive Sampling yakni peneliti menetapkan lebih awal siapa saja yang menjadi sampelnya dan menyebutkan statusnya masing - masing sesuai dengan keinginan dan tujan peneliti (Mukhtar, 2013).

Analisis data yang digunakan dalam penelitian ini yakni analisis deskriptif kualitatif yaitu pengelolaan data dengan mencari gambaran umum dari data hasil penelitian, membandingkan data yang didapat serta mencari hubungan setiap data yang diperoleh, sehingga menghasilkan kesimpulan akhir mengenai penelitian yang dilakukan (Arikunto, 2010). 


\section{HASIL DAN PEMBAHASAN}

DTW Alas Kedaton merupakan destinasi wisata yang bernuansa alam. Daya tarik yang ditawarkan yakni keasrian Hutan Alas Kedaton beserta isinya seperti kera-kera dan kelelawar (kalong). Di dalam hutan Alas Kedaton juga terdapat sebuah pura yang bernama Pura Dalem Kahyangan Kedaton yang unik dan memiliki daya tarik tersendiri. DTW Alas Kedaton berlokasi di Desa Kukuh, Kecamatan Marga, Kabupaten Tabanan. Kurang lebih $\pm 19,1 \mathrm{~km}$ (37 menit) dari Kota Denpasar dan $\pm 36,6 \mathrm{~km}$ dari Bandara Ngurah Rai.

\section{Pengelolaan DTW Alas Kedaton} awalnya dikelola secara langsung oleh masyarakat lokal. Seiring perjalanannya, karena perkembangan pariwisata di DTW Alas Kedaton semakin meningkat maka pada tahun 2012 dibentuk organisasi Manajemen Pengelola yang bertugas untuk megelola DTW Alas Kedaton yang terdiri dari beberapa karyawan seperti karyawan loket/tiket, security/pecalang, tukang sapu dan lain-lainnya dibawah pimpinan seorang Manajer Operasional. Manajemen Pengelola tersebut juga didampingi oleh Bendesa Adat sebagai penanggung jawab.

Kepengelolaan yang diterapkan di

DTW Alas Kedaton tidak melibatkan masyarakat lain atau masyarakat luar jadi setiap karyawan maupun manajernya yang bekerja di DTW Alas Kedaton adalah warga masyarakat lokal Desa Kukuh. Dalam pengelolaanya, pihak Desa Adat beserta pihak Manajemen Pengelola menjaga kelestariannya serta mengembangkannya dengan cara membangun sarana dan prasarana penunjang pariwisata seperti, lahan parkir, toko cinderamata (art shop) dan toilet. Dimana sarana dan prasarana penunjang pariwisata tersebut diperuntukkan untuk memberikan kenyamanan serta kepuasan bagi wisatawan yang berkunjung ke DTW Alas Kedaton.

Upaya Pengembangan kepariwisataan di DTW Alas Kedaton, pihak Manajemen Pengelola melakukan kerjasama dengan Pemkab Tabanan dalam penyelenggaraan dan pengelolaan DTW Alas Kedaton, dalam pembagian hasilnya pihak pengelola membayar retribusi sebesar $20 \%$ dari hasil penerimaan pendapatan tiket masuk setiap bulan ke Pemkab Tabanan. Adapun harga tiket masuk ke DTW Alas Kedaton yaitu untuk wisatawan mancanegara per orangnya yakni Rp.15.000 (dewasa) dan Rp.10.000 (anak) sedangkan untuk wisatawan nusantara per orangnya yakni Rp.10.000 (dewasa) dan Rp.7.500 (anak).

Upaya kegiatan pengelolaan dan pengembangan yang dilakukan di DTW Alas Kedaton adalah dalam bentuk upaya pembenahan - pembenahan seperti berikut :

\section{Upaya Pembenahan Kedalam}

Upaya pembenahan dalam ini yang dimaksud adalah usaha untuk meningkatkan kualitas pelayanan (hospitality) yang diberikan dan disediakan, yakni melakukan usaha untuk melakukan binaan kepada masyarakat atau karyawan yang bekerja di DTW Alas Kedaton seperti binaan tentang bagaimana melakukan tugasnya dengan benar serta bagaimana cara berinteraksi dengan wisatawan yang baik dan melakukan perbaikan serta perawatan dari saranaprasarana penunjang pariwisata yang ada di DTW Alas Kedaton seperti : perbaikan jalan, tempat parkir, tempat bermain, tempat rekreasi, perbaikan toilet dan wantilan.

2. Upaya Pembenahan Keluar

Upaya pembenahan luar ini yang dimaksud adalah usaha untuk menjalin hubungan dengan pihak luar dalam memperkenalkan atau mempromosikan DTW Alas Kedaton kepada seluruh masyarakat luas agar mengetahui dan tertarik untuk mengunjungi DTW Alas Kedaton seperti melakukan pendekatan - pendekatan dengan pihak luar seperti agent tour \& travel, sopir guide dari luar, dan biro perjalanan pariwisata. Selain menjalin hubungan dengan pihak agent luar, pihak Manajemen Kepengelolaan di DTW Alas Kedaton juga memanfaatkan media sebagai tempat promosi seperti media elektronik seperti televisi, media cetak seperti koran dan majalah, penyebaran browser serta mengikuti pagelaran pameran daerah maupun nasional dalam ajang mempromosikan DTW Alas Kedaton.

Upaya pihak Manajemen Pengelola dalam melakukan pembenahan - pembenahan untuk mengembangkan DTW Alas Kedaton juga mengalami kendala yakni dari sisi perawatan sarana prasarana penunjang pariwisata yang ada di DTW Alas Kedaton seperti jalan setapak, parkir, tempat bermain, tempat rekreasi, dan wantilan yang sudah berumur atau mengalami 
kerusakan. Sarana prasarana penunjang tersebut memang sudah seharusnya atau selayaknya dilakukan perbaikan atau renovasi akan tetapi karena keterbatasan dari sisi pendanaan jadi pihak Manajemen Pengelola melakukan perbaikan dan perawatan sarana prasarana penunjang tersebut dengan cara perbaikan dan perawatan bertahap sesuai dengan dana yang dimiliki.

Upaya kegiatan pengembangan pariwisata di DTW Alas Kedaton tidak lepas dari keterlibatan dan peranan masyarakat lokal sebagai pemilik destinasi. Minat dari warga masyarakat lokal Desa Kukuh untuk ikut berperan dan terlibat dalam kegiatan kepariwisataan di DTW Alas Kedaton sangat tinggi akan tetapi karena tenaga kerja yang dibutuhkan dalam pengelolaan di DTW Alas Kedaton tidak begitu banyak jadi pihak Manajemen Pengelola menggunakan sistem kontrak karyawan 3 tahun dimana di masing masing setiap Banjar yang ada di Desa Kukuh dilakukan pemerataan bahwa disetiap Banjar di Desa Kukuh diberikan jatah 2 orang bagi setiap warga banjarnya yang ingin ikut berperan dan terlibat atau menjadi karyawan di Daya Tarik Wisata Alas Kedaton. Jika nanti masa kerja 3 tahunnya sudah selesai maka akan diganti dengan warga perwakilan dari banjar tersebut dengan catatan ketika 3 tahun masa kerjanya sudah selesai akan tetapi utusan warga yang mewakili banjar tersebut tidak ada penggantinya jadi karyawan atau petugas sebelumnya diperbolehkan untuk melanjuti tetapi jika ada penggantinya karyawan sebelumnya akan diganti.

Adapun peranan dari masyarakat lokal Desa Kukuh dalam pengelolaan DTW Alas Kedaton yakni dapat dikelompokkan menjadi 4 kegiatan, yaitu sebagai berikut :

1. Peranan masyarakat dalam kegiatan perencanaan.

Kegiatan perencanaan di DTW Alas Kedaton biasanya dilakukan oleh pihak Manajemen Pengelola yakni Manajer Operasional dan Bendesa Adat, tetapi masukan pendapat atau ide dan saran-saran dari masyarakat tetap didengarkan dan diperhatikan. Peranan masyarakat lokal Desa Kukuh dalam kegiatan perencanaan di Daya Tarik Wisata Alas Kedaton bersifat konsultatif, yaitu memberikan saran kepada pihak Manajemen Pengelola mengenai suatu permasalahan yang mereka temui dilapangan. Saran tersebut didengar akan tetapi belum tentu dilaksanakan oleh pihak pengelola sebelum melalui pertimbangan pertimbangan atau melalui musyawarah mufakat.

2. Peranan masyarakat dalam kegiatan pengorganisasian.

Masyarakat lokal Desa Kukuh secara langsung dilibatkan dalam Pengelolaan di DTW Alas Kedaton, karena memang dikelola oleh masyarakat lokal Desa Kukuh. Dalam peranannya, masyarakat yang ikut terlibat dalam kegiatan kepariwisataan di DTW Alas Kedaton diberdayakan sebagai petugas kebersihan, pemandu lokal, petugas loket, petugas keamanan, Kelompok Sadar Wisata (Pokdarwis), Kelompok Pedagang Alas Kedaton (KPAK) yang berdagang makanan, minuman, pakaian, souvernir, patung, lukisan dan lain-lainnya.

3. Peranan masyarakat dalam kegiatan pergerakan orang - orang.

Bendesa Adat dan Manajer Operasional mempunyai peranan yang besar dalam memberikan pengarahan, pembenahan dan pembinaan kepada masyarakat Desa Kukuh yang ikut terlibat dalam kegiatan kepariwisataan DTW Alas Kedaton melalui pertemuan atau rapat dalam upaya pengelolaan dan pengembangan kepariwisataan DTW Alas Kedaton.

4. Peranan masyarakat dalam kegiatan pengawasan.

Kegiatan pengawasan kepariwisataan di DTW Alas Kedaton dilakukan oleh Manajer Operasional dan diawasi oleh Bendesa Adat sebagai penanggung jawab. Peranan masyarakat lokal Desa Kukuh dalam pengawasan DTW Alas Kedaton dilakukan dengan membentuk kelompok pengamanan kawasan secara mandiri seperti Kelompok Sadar Wisata (Pokdarwis) dan pecalang.

\section{SIMPULAN}

Berdasarkan pokok permasalahan yang dibahas dalam penelitian, dapat ditarik simpulan, yaitu :

Pengelolaan DTW Alas Kedaton dari awal memang dikelola oleh masyarakat lokal Desa Kukuh. Kegiatan pengelolaan kepariwisataan di DTW Alas Kedaton seperti perencanaan, pengorganisasian, pergerakan, 
dan pengawasan hanya melibatkan masyarakat lokal. Peranan masyarakat Desa Adat Kukuh dalam pengelolaan dan pengembangan pariwisata di DTW Alas Kedaton yaitu selain menjadi anggota Manajemen Pengelola masyarakat lokal diberdayakan menjadi karyawan loket, petugas kebersihan, pemandu lokal, petugas keamanan, Kelompok Pedagang Alas Kedaton (KPAK) yang berdagang makanan, minuman, pakaian, souvernir, patung, lukisan dan lain-lainnya. Serta membentuk organisasi mandiri seperti Kelompok Sadar Wisata (Pokdarwis) yang terdiri dari masyarakat yang sadar dan secara relawan peduli akan kegiatan kepariwisataan DTW Alas Kedaton.

\section{SARAN}

Berdasarkan hasil dan pembahasan penelitian, maka dapat disampaikan saran sebagai berikut :

Dalam meningkatkan keterlibatan dan peranan masyarakat lokal Desa Kukuh, pihak Manajemen Pengelola perlu melakukan pembinaan lebih serta pembenahan yang berkelanjutan kemasyarakat yang terlibat didalam kegiatan kepariwisataan DTW Alas Kedaton dengan melakukan sosialisasi kemasyarakat mengenai arti dan perlunya pariwisata dalam mendukung pengembangan DTW Alas Kedaton agar masyarakat lokal Desa Kukuh sadar akan wisata dan menerapkan Sapta Pesona untuk mendukung pengembangan DTW Alas Kedaton.

\section{DAFTAR PUSTAKA}

Anonim. 2009. Undang-Undang Republik Indonesia No. 10 tentang kepariwisataan.

Arikunto, Suharsimi. 2010. Prosedur Penelitian Suatu Pendekatan Praktek. Jakarta: Rineka Cipta.

George R.T. 2000. Prinsip-prinsip Manajemen. (edisi bahasa Indonesia). Bandung: PT Bumi Aksara.

Lawang, R.M.Z. 1992. Hubungan Kewenangan Desa Kabupaten. FISIP Press.

Mukhtar. 2013. Metode Penelitian Deskriftif Kualitatif. Jakarta : GP Press Group.

Soekanto, S. 1990. Sosiologi Suatu Pengantar. Jakarta. PT. Raja Grafindo Persada.

Sugiyono. 2012. Metode Penelitian Kuantitatif Kualitatif dan $R \& D$. Bandung: Penerbit Alfabeta.

Terry, George R. 2009. Prinsip-prinsip Manajemen. Jakarta: Penerbit Bumi Aksara. 